\title{
DESEMPENHO DE SEMENTES DE SAPOTI (Achras sapota L.) SUBMETIDAS A DIFERENTES TRATAMENTOS PRÉ-GERMINATIVOS. ${ }^{1}$
}

\author{
GILVANEIDE ALVES DE AZERÊDO², RISELANE DE LUCENA ALCÂNTARA BRUNO³, \\ KILSON PINHEIRO LOPES ${ }^{2}$, ACILON DA SILVA² E GENILDO BANDEIRA BRUNO³.
}

\begin{abstract}
RESUMO - O sapotizeiro (Achras sapota L.) é cultivado principalmente para a produção de frutos, encontrando-se entre os mais apreciados pela população das áreas onde cresce. Sua propagação pode dar-se através de enxertia ou diretamente por sementes, dando origem aos chamados pés-francos. Considerando o fato de que muitas das espécies florestais e frutíferas apresentam o fenômeno de dormência, e diante da necessidade de se intensificar estudos que melhor expliquem tal processo, o objetivo deste trabalho foi avaliar a eficiência de diferentes tratamentos pré-germinativos em sementes de sapoti, visando a acelerar e uniformizar a germinação de suas sementes. O ensaio foi conduzido em casa de vegetação do Departamento de Fitotecnia, CCA/UFPB, Areia-PB, sendo utilizados os seguintes tratamentos: imersão em água a $60^{\circ} \mathrm{C}$ por 1,2 e 3 minutos; corte lateral (ao embrião) com e sem embebição em água por 24 horas; corte distal (ao embrião) com e sem embebição em água por 24 horas; corte lateral+distal (ao embrião) com e sem embebição em água por 24 horas e a testemunha (ausência de tratamento). Efetuados os tratamentos, foi realizada a semeadura em bandejas contendo areia lavada e autoclavada, utilizando-se de quatro repetições de 25 sementes. As características avaliadas foram: percentagem e índice de velocidade de emergência, comprimento de raiz e de hipocótilo e peso de matéria seca de planta. O delineamento experimental foi o Inteiramente Casualizado, e os contrastes entre as médias foram realizados através do teste de Duncan, ao nível de $5 \%$ de probabilidade. As sementes de sapoti exibiram maior emergência $(81 \%)$ e índice de velocidade de emergência $(0,58)$ quando submetidas ao corte lateral, sem embebição. $O$ corte das sementes seguido de embebição por 24 horas não foi eficiente para acelerar a emergência e o índice de velocidade de emergência de plântulas de sapoti. A imersão em água a $60^{\circ} \mathrm{C}$, independentemente do tempo utilizado, não deve ser recomendada como tratamento pré-germinativo para sementes de sapoti.
\end{abstract}

Termos para indexação: vigor, dormência, frutífera exótica.

\section{PERFORMANCE OF PRE-TREATED SEEDS OF SAPODILLA (Achras sapota L.).}

\begin{abstract}
The sapodilla is an important fruit tree and the fruits produced are very appreciated by consumers. The plant is propagated either via grafting or directly via seeds. In the latter case, the phenomenon of dormancy has delayed or provoked the lack of uniformity of plantations. Taking into account the fact that many forest and fruit species present the phenomenon of dormancy, and considering the necessity of further studies that might explain this process better, the objective of the present work was to evaluate the efficiency of different pre-treatments aiming accelerating and promoting the uniformity of sapodilla seeds germination. The experiment was carried out in the greenhouse of the Department of "Fitotecnia", CCA/UFPB, Areia, Paraíba State. The pre-treatments consisted of: 1 . total immersion of the sapodilla seeds in water $\left(60^{\circ} \mathrm{C}\right)$ for 1,2 and 3 minutes; 2 . lateral cut to the embryo seeds with and without later immersion, in water (room temperature) for 24 hours; 3 . peripheral cut to the embryo seeds with and without later immersion, in water (room temperature) for 24 hours; 4 . lateral and peripheral cut to the embryo seeds, with and without later immersion, in water (room temperature) for 24 hours, and control (lack of treatment). After the treatments were carried out, the seeds were sowed in trays containing sterilized sand with four repetitions of 25 seeds. The vigor was evaluated in terms of percentage and index of emergence, root and hipocotyl length and the weight of the plants dry substance. The experimental delineation was randomized and the contrasts resulting from the averages were undertaken through the Duncan test at the level of 5\% of probability. The sapodilla seeds revealed greater emergency $(81 \%)$ and speed rate of emergency $(0,58)$ when submitted to lateral cut, without immersion. The cut of the seeds followed by immersion for 24 hours was not efficient to accelerate the emergency and the emergency speed rate of sapodilla plants. The greatest vigor was obtained by the non-immersed seeds cut laterally to the embryo. The seeds which were immersed in water $\left(60^{\circ} \mathrm{C}\right)$ for 1,2 and 3 minutes presented the least vigor.
\end{abstract}

Index terms: vigor, dormancy, exotic fruits.

1 (Trabalho 190/2000). Recebido: 01/09/2000. Aceito para publicação: 21/09/2001.

2 Eng $^{\text {os }}$. Agros. Mestrandos em Produção Vegetal. Depto. de Fitotecnia - CCA/UFPB. Areia-PB. 58397-000

3 Prof $^{\text {es }}$. Adjuntos do Departamento de Fitotecnia - CCA/UFPB. Caixa Postal 22. E-mail: lane@ cca.ufpb.br 


\section{INTRODUÇÃO}

O sapotizeiro (Achras sapota L.) é uma espécie exótica no Brasil (Moura et al., 1983), sendo cultivado na região Nordeste, principalmente para consumo de frutos "in natura", e para a industrialização de sucos, sorvetes e geléias. Em virtude do ótimo sabor e aroma apresentados, alcançam elevados preços nos mercados regionais (Guia Rural, 1991). Essa espécie tem sido usada também na medicina popular, em que componentes das sementes e da casca dos ramos, que apresentam propriedades diuréticas e antipiréticas, são empregados para dissolver cálculos hepáticos, nefríticos e combater a anorexia (Cordeiro et al., 1996).

Para justificar o presente estudo, considera-se principalmente o potencial e as possibilidades para exploração dessa frutífera e, conseqüentemente, sua expansão na região Nordeste. Para isso, entende-se que as sementes devem, de início, ser objeto primordial a ser estudado.

Considerando que a germinação das sementes de sapoti ocorre lenta e tardiamente (estudos preliminares), o presente trabalho teve como objetivo testar diferentes tratamentos prégerminativos, visando a uniformizar e acelerar a emergência de plântulas.

\section{MATERIAL E MÉTODOS}

O trabalho foi conduzido em casa de vegetação, no Departamento de Fitotecnia do Centro de Ciências Agrárias da UFPB, Areia-PB, no período de 29/02 a 19/05 de 2000. As sementes de sapoti foram obtidas de frutos colhidos no estádio "de vez", a partir de matrizes localizadas no município de Pilõezinhos-PB. Os frutos foram mantidos no ambiente de laboratório a uma temperatura de $28^{\circ} \mathrm{C}$ e $65 \%$ de umidade relativa, tardando em torno de 12 dias para que atingissem o amadurecimento total (pericarpo amolecido ao tato), procedendo-se a extração das sementes. Em seguida, as mesmas foram postas para secar à sombra, sobre folhas de papel jornal durante cinco dias. Os tratamentos pré-germinativos foram os seguintes: $T_{1}$, imersão em água a $60^{\circ} \mathrm{C}$ por 1 minuto; $\mathrm{T}_{2}$, imersão em água a $60^{\circ} \mathrm{C}$ por 2 minutos; $\mathrm{T}_{3}$, imersão em água a $60^{\circ} \mathrm{C}$ por 3 minutos; $\mathrm{T}_{4}$, corte lateral ao embrião, seguido de embebição em água por 24 horas; $\mathrm{T}_{5}$, corte lateral ao embrião, sem embebição; $\mathrm{T}_{6}$, corte distal ao embrião, seguido de embebição em água por 24 horas; $\mathrm{T}_{7}$, corte distal ao embrião, sem embebição; $\mathrm{T}_{8}$, corte lateral+distal ao embrião, seguido de embebição em água por 24 horas; $\mathrm{T}_{9}$, corte lateral+distal ao embrião, sem embebição; e $\mathrm{T}_{10}$, Testemunha (ausência de tratamento). $\mathrm{O}$ corte no tegumento foi efetuado utilizando-se de estilete, conforme ilustra a Figura 1.

Após os tratamentos, as sementes foram colocadas em bandejas com dimensões de $45 \mathrm{~cm} \times 30 \mathrm{~cm} \times 7 \mathrm{~cm}$, contendo areia lavada e autoclavada. Diariamente, realizaram-se irrigações com regador manual, para manter a umidade do substrato. Foram avaliadas as seguintes variáveis: percentagem de emergência (realizada aos 45 dias); índice de velocidade de emergência (IVE) com registro do número de plântulas emersas diariamente a partir do $20^{\circ}$ até o $45^{\circ}$ dia; comprimentos de raiz e hipocótilo; e peso de matéria seca de planta, aos 60 dias após emergência. O IVE foi calculado segundo fórmula proposta por Maguire (1962).

$\mathrm{O}$ delineamento experimental foi o Inteiramente
Casualizado, constando de 10 tratamentos e quatro repetições com 25 sementes. Os dados foram expressos em percentagem, e a análise de variância foi efetuada aplicando-se o teste $F$, sendo as médias dos tratamentos comparadas pelo teste de Duncan, ao nível de 5\% de probabilidade.

\section{RESULTADOS E DISCUSSÃO}

Com base na análise de variância (Tabela 1), observa-se que houve efeito significativo em todas as características avaliadas ao nível de $1 \%$ de probabilidade pelo teste $\mathrm{F}$, exceto para peso de matéria seca de planta (5\%).

Quanto à percentagem de emergência de plântulas e IVE (Tabela 2), constatou-se que os maiores valores $(81 \%$ e 0,58 , respectivamente) foram verificados com as sementes submetidas ao corte lateral sem embebição. Esses valores diferiram estatisticamente dos obtidos com as sementes imersas em água a $60^{\circ} \mathrm{C}$, e daquelas que sofreram cortes lateral, distal e lateral+distal, com embebição por 24 horas. Resultados contraditórios foram obtidos por Firmino et al. (1997), em sementes de cajá (Spondias lutea L.), onde não encontraram diferença significativa com relação à percentagem de emergência para os três tipos de escarificação (distal, proximal e proximal+distal ao embrião) e períodos de embebição (2, 4 e 6 horas) estudados; no entanto, observaram que a escarificação realizada na região proximal+distal ao embrião, durante 2 horas de embebição, promoveu uma maior percentagem de emergência em relação aos demais tratamentos. Por outro lado, Souza \& Varela (1989) constataram que, em sementes de orelha-de-macaco (Enterolobium schomburgkii Benth), os tratamentos submetidos ao corte do lado oposto à emissão da radícula e à escarificação manual foram eficientes, porém, não diferiram significativamente em relação à percentagem de germinação. Em sementes de mulungu (Erithrina speciosa Andr.), Carvalho et al. (1980) verificaram que a escarificação próxima à extremidade das sementes acelerou a germinação, resultando em plântulas mais vigorosas. Em cajá, a maior velocidade de emergência foi alcançada com as sementes despontadas na região proximal ao embrião (Firmino et al., 1997).

Pode-se observar ainda, na Tabela 2, que a imersão em água a $60^{\circ} \mathrm{C}$, independentemente do tempo utilizado, foi extremamente prejudicial à qualidade fisiológica das sementes, apresentando valores abaixo de 25\% (emergência) e 0,12 (IVE). Verificou-se que os tratamentos constituídos por cortes seguidos de embebição foram pouco efetivos, apresentando valores de emergência e IVE inferiores a $35 \%$ e 0,22 , respectivamente; principalmente quando comparados com aqueles não submetidos a embebição que, apesar de não diferirem do tratamento corte lateral+distal ao embrião, sem embebição, exibiram valores considerados elevados; e também com a testemunha, cujas sementes não foram submetidas a nenhum tipo de tratamento pré-germinativo, e não obstante, apresentaram uma superioridade, em termos absolutos, em relação aos tratamentos seguidos de embebição. Varela \& Ferraz (1991), estudando sementes de pau-de-balsa (Ochroma pyramidale (Cav.ex Lam.) Urb, verificaram que a velocidade de germinação foi maior quando utilizaram a escarificação manual e imersão em água durante 6 horas. 
TABELA 1 - Análise de variância dos tratamentos pré-germinativos efetuados nas sementes de sapoti (Achras sapota L.).

\begin{tabular}{|c|c|c|c|c|c|c|}
\hline $\begin{array}{c}\text { Fontes de } \\
\text { variação }\end{array}$ & \multicolumn{6}{|c|}{ Quadrados médios } \\
\hline Tratamento & 9 & $28,49167 * *$ & $0,00117 * *$ & $0,77300 * *$ & $0,19767 * *$ & $0,00108 *$ \\
\hline Resíduo & 30 & 854,7500 & 0,0353 & 23,1904 & 5,9301 & 0,0325 \\
\hline \multicolumn{7}{|c|}{$\begin{array}{l}\text { ns - não significativo. } \\
* * \text { - Significativo a } 1 \% . \\
* \text { - Significativo a } 5 \% .\end{array}$} \\
\hline $\mathrm{T}_{1}$ & & $15 \mathrm{bc}$ & $0,09 \quad \mathrm{bc}$ & 5,69 & 2,75 & 0,15 \\
\hline $\mathrm{T}_{2}$ & & $12 \mathrm{c}$ & $0,06 \quad \mathrm{c}$ & 4,29 & 2,78 & 0,19 \\
\hline $\mathrm{T}_{3}$ & & $22 \mathrm{bc}$ & $0,12 \quad \mathrm{bc}$ & 6,15 & 3,55 & 0,18 \\
\hline $\mathrm{T}_{4}$ & & $32 \mathrm{bc}$ & $0,21 \quad \mathrm{bc}$ & 6,37 & 4,01 & 0,21 \\
\hline $\mathrm{T}_{5}$ & & 81 a & 0,58 a & 7,68 & 4,14 & 0,23 \\
\hline $\mathrm{T}_{6}$ & & $33 \mathrm{bc}$ & $0,21 \quad b c$ & 7,01 & 3,82 & 0,21 \\
\hline $\mathrm{T}_{7}$ & & $61 \mathrm{ab}$ & $0,41 \mathrm{ab}$ & 6,00 & 4,00 & 0,21 \\
\hline
\end{tabular}

Médias seguidas da mesma letra não diferem estatisticamente entre si, ao nível de 5\% de probabilidade, pelo teste de Duncan.

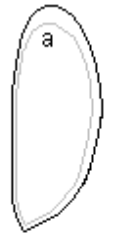

1

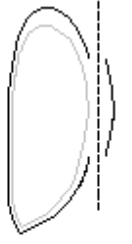

2

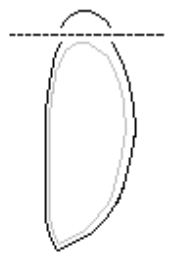

3

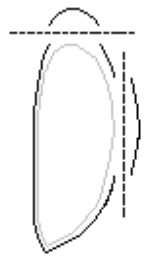

4
FIGURA 1 - Tipos de corte realizados em sementes de sapoti (Achras sapota L.). 1, semente intacta; 2, corte lateral ao embrião; 3, corte distal ao embrião; 4, corte lateral+distal ao embrião; a, embrião.

Os resultados observados constituem um indicativo dos efeitos deletérios causados pela embebição das sementes por 24 horas, os quais podem ser atribuídos à perda de parte dos constituintes celulares por lixiviação para o exterior da célula (Leopold, citado por Vieira \& Carvalho, 1994), ou provavelmente à redução na disponibilidade de oxigênio em condição de temperatura elevada $\left(28^{\circ} \mathrm{C}\right)$ durante a embebição das sementes, segundo afirma Popinigis (1985). Este autor constata que, no processo de embebição em água, a reidratação das macromoléculas e organelas celulares proporcionam o aumento das atividades respiratórias da semente e causam, com isto, o aparecimento imediato de avidez das células por oxigênio.

Quanto aos comprimentos de raiz, de hipocótilo e peso de matéria seca de plantas (Tabela 2), não se constataram diferenças significativas para nenhuma destas características. Tais resultados divergem de Sarmento (1997) em sementes escarificadas de cajá, as quais produziram plantas com maior peso de matéria seca de raiz e de folhas. Entretanto, pode-se observar que o corte lateral sem embebição e a imersão em água a $60^{\circ} \mathrm{C}$, nos diferentes tempos, expressaram, em geral, os maiores e menores valores de vigor, respectivamente, reforçando os resultados obtidos em relação à emergência e ao índice de velocidade de emergência de plântulas.

Com base nos resultados obtidos no presente trabalho, sugerem-se novos estudos com o emprego de outros tratamentos pré-germinativos, incluindo menores períodos de embebição, no sentido de se obter maiores respostas na emergência e no vigor de sementes de sapoti.

\section{CONCLUSÕES}

Nas condições em que o presente trabalho foi realizado, os resultados permitem concluir que: 
1) As sementes de sapoti exibem maior percentual e índice de velocidade de emergência quando submetidas ao corte lateral ao embrião, sem embebição.

2) O corte das sementes, seguido de embebição por 24 horas, não foi eficiente para acelerar a emergência e o seu índice de velocidade, nas plântulas de sapoti.

3) A imersão em água a $60^{\circ} \mathrm{C}$ por 1,2 e 3 minutos não deve ser recomendada como tratamento pré-germinativo de sementes de sapoti.

\section{AGRADECIMENTOS}

Os autores agradecem à Professora Genilda Alves de Azerêdo, da Universidade Federal da Paraíba, pelas valiosas contribuições.

\section{REFERÊNCIAS BIBLIOGRÁFICAS}

CARVALHO, N.M.; DEMATÊ, M.E.S.P.; GRAZIANO, T.T. Germinação de sementes de essências florestais nativas. 1. Suinã ou Mulungu (Erithrina speciosa Andr.). Revista Brasileira de Sementes, Brasília. v.2, n.1, p.81-87. 1980.

CORDEIRO, R.; NUNES, V. do A.; ALMEIDA, C.R. Plantas que curam. São Paulo: Grupo de comunicação Três, 1996. 390p.

FIRMINO, J.L.; ALMEIDA, M.C.; TORRES, S.B. Efeito da escarificação e da embebição sobre a emergência e desenvolvimento de plântulas de cajá (Spondias lutea L.). Revista Brasileira de Sementes, Brasília. v.19, n.1, p.125-
128.1997.

GUIA RURAL, Plantar. A Enciclopédia da Agricultura Brasileira. São Paulo: Abril, 1991. 225p.

MAGUIRE, J.D. Speed of germination aid in selection and evaluation for seedling emergence and vigor. Crop Science, Madison, v.2, n.1, p.176-177, 1962.

MOURA, R.J.M.; BEZERRA, J.E.F.; SILVA, M. de A.; CAVALCANTE, A.T. Comportamento de matrizes de sapotizeiro. Revista Brasileira de Fruticultura, Cruz das Almas, v.5. p.103112. 1983.

POPINIGIS, F. Fisiologia da semente. Brasília: AGIPLAN, 1985. 289p.

SARMENTO, F.S.G. Influência do tamanho da semente e de métodos de quebra de dormência na germinação e formação de mudas de cajazeira (Spondias lutea S.). (Trabalho de Agronomia) - Universidade Federal da Paraíba, Areia, 1997.

SOUZA, S.G.A., VARELA, V.P. Teste pré-germinativo em sementes de orelha-de-macaco (Enterolobium schombumgkii Benth). Acta Amazonica, Manaus, v.19, n.único, p.19-26. 1989.

VARELA, V.P., FERRAZ, I.D.K. Germinação de sementes de paude-balsa. Pesquisa Agropecuária Brasileira, Brasília, v.26, n.10, p.1685-1689, 1991.

VIEIRA, R.D, CARVALHO, N.M. Testes de vigor em sementes. Jaboticabal: FUNEP, 1994. 164p. 